\title{
Doing the 'right' thing as a GI consultant
}

\author{
Robert Butcher PhD ${ }^{1}$, Paul C Adams MD²
}

$\mathrm{R}_{\mathrm{cos}}^{\mathrm{ob}}$ obert Butcher is an ethicist at London Health Sciences Centre, London, Ontario. Since 1990, he has worked as an ethics consultant in health care. He currently works with 24 hospitals and health care facilities, and he developed and presents the Ethics Education Programme for the Canadian Council on Health Services Accreditation.

PA: As a gastrointestinal consultant, we are wearing many hats: we try to help the patient, we have some obligations to our hospital and to our health care system, and many of us are running a business. Does this create ethical problems?

RB: The 'many hats' problem always creates the possibility of a conflict of interest. The role of the physician as a patient advocate may conflict with the role of the physician as a researcher, or physician as a gatekeeper to a publicly funded health care system, or physician-manager in a health care facility, or of course, the more regular conflicts with the physician as a businessperson, family member or friend. Multiple roles

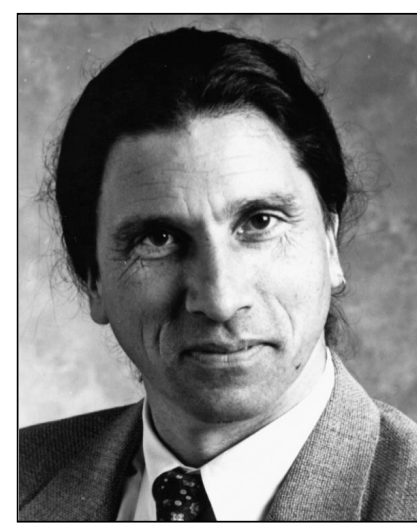

Robert Butcher is an ethicist at London Health Sciences Centre, London, Ontario
RB: This is another of those conflicts of interest. We expect physicians to be patient advocates (the fiduciary relationship to each patient), yet we also expect physicians to act as gatekeepers to the medical system and, in effect, to make resource decisions not on the basis of just the individual patient, but on behalf of future or prospective patients. I have long argued that this puts physicians in a hopelessly compromised position. I prefer the simplicity (and purity) of a system in which my physician is charged with looking out for my interests. Someone else - hospital administration, small 'p' politicians - can work out the range of options within which my physician has to work. What I'm uncomfortable with is the idea that my physician should be working out resource allocation decisions, on behalf of others, as he or she tends me at my bedside. What I want to do is separate the resource decisions from the medical decisions and give the medical decisions to the physician and the patient, leaving the resource decisions somewhere else.

PA: Our hospitals may ask us not to use newer disposable endoscopic accessories because they are too expensive and, yet, they may be the best available care for our patients. Are we advocating for the patient or the hospital budget?

RB: This is the same problem. The Canadian medical system chooses not to do the very best for any individual patient countless times every day. I sometimes say that "no, we won't" (rather than "no, we can't") are the hardest words to utter in health care. If there are limited resources for health care (and there are), and if there is unlimited demand (and there is) we will always be in a position of having to say "no, we won't". The important question is who decides to say "no, we won't", and how does that decision get made? The phrasing of your original question is interesting - "The hospital ... asks...". This shows an unwillingness to acknowledge who owns the decision. The real issue is should disposable endoscopic accessories be unavailable for use by all physicians in hospital $\mathrm{x}$ (or within health care system/province y).

PA: Many of our patients request disability forms. This also raises the question about whether we are working for the system or the patient. Should disability be assessed by an independent agency?

RB: This is another conflict of interest. The community has granted physicians a level of trust that is, I'd say, quite What kinds of ethical problems does this introduce?

\footnotetext{
${ }^{1}$ Foundations: Consultants on Ethics and Values Canada, Inc, Ilderton; ${ }^{2}$ Department of Medicine, London Health Sciences Centre, London, Ontario

Correspondence: Dr Robert Butcher, Foundations: Consultants on Ethics and Values Canada, Inc, 180 Quaker Lane, RR\#2, Ilderton, Ontario NOM 2A0. Telephone 519-666-2253, fax 519-666-0590, e-mail rbutcher@uwo.ca
} 
unprecedented in the rest of the community. In this case, the expectation is that the physician can provide an independent, objective assessment of the person's physical state. The physician is playing the role of objective, neutral gatekeeper to a financial system.

Can physicians do that and still be patient advocates? I don't know the answer to that question. I'd say this is one of those issues in which physicians themselves have to decide if they are prepared to, or capable of, fulfilling that role with the objectivity that is required. Physicians, as a group, could decide that this practice has the potential to compromise the integrity of the patient and physician relationship and so should be avoided.

Perhaps I can give you an example. I was part of a decisionmaking team that was deciding whether a hospital should cover the cost of a drug treatment for a patient. (The drug was not covered for that use by the provincial drug plan.) The decision, made by a team that included managers and physicians, was made, in part, on the grounds of cost and cost-effectiveness. The cost of the drug was relatively low and the prospect of benefit relatively high. The chief-of-staff wanted scientific criteria and a decision-making process that left out cost considerations. But, for this type of decision, considerations of cost and costeffectiveness are crucial for the management team. Should we fund it, knowing that if we fund this new product in the hospital, some other product for some other patient will not get funded because of the fixed health care budget?

PA: Most Canadian gastroenterologists seem to have an unlimited supply of patients. In American urban centres with a high density of specialists, there is a pressure to provide endoscopy and/or therapies based on pressure from the patient or referring physician rather than on your best clinical judgment. This is the pressure to maintain a successful business. Does this create an ethical dilemma?

RB: We've spoken about the tension between the role of the physician as a patient advocate, and gatekeeper to a medical system, and the physician as a businessperson. Let's take a slightly different approach here. What happens if the patient feels he or she needs or wants some diagnostic intervention or treatment that you, in your professional judgment think is not required? Should you deny that service or treatment to the patient? And, does it matter if the service is paid for by the patient or by a third party? I would argue that a physician should not provide any treatment that is not going to benefit the patient. The patient may have a quite different view of what he or she thinks counts as a benefit. I think the professional role of the physician is not simply to act as a service provider doing what he or she is requested to do by the patient. Does it matter who gets to pay? I'd say no, although I think the issue is far more powerful in a publicly funded system. In a publicly funded system, if one patient gets a treatment that will not work (if the resources are wasted on that person), then someone else is harmed by not having those resources available to be effectively used for them. Waste on this patient harms other patients, and that unnecessary harm should be avoided.

PA: We may be headed into two-tier medical care in Canada in the future. You have had first-hand experience with this in Britain. You can pay and have a colonoscopy tomorrow, or go on a waiting list in the public system and wait for months.

RB: We already have a system that is two- (or many-) tiered. Some medical services are funded, and others, often just as necessary, are not. I think it would be enough to say that I start from a position that celebrates individual freedom. That is, I think we ought to create a community where people are as free as possible to make their own choices. Our freedom of choice is, of course, limited in all sorts of ways, the most obvious of which is if our free choices harm or restrict the choices of others. I believe that those who would restrict liberty should be required to show why liberty should be restricted. Let's just say that I have not been convinced by the arguments that have been put forward so far in the Canadian health care system. 


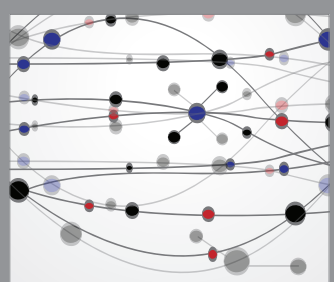

The Scientific World Journal
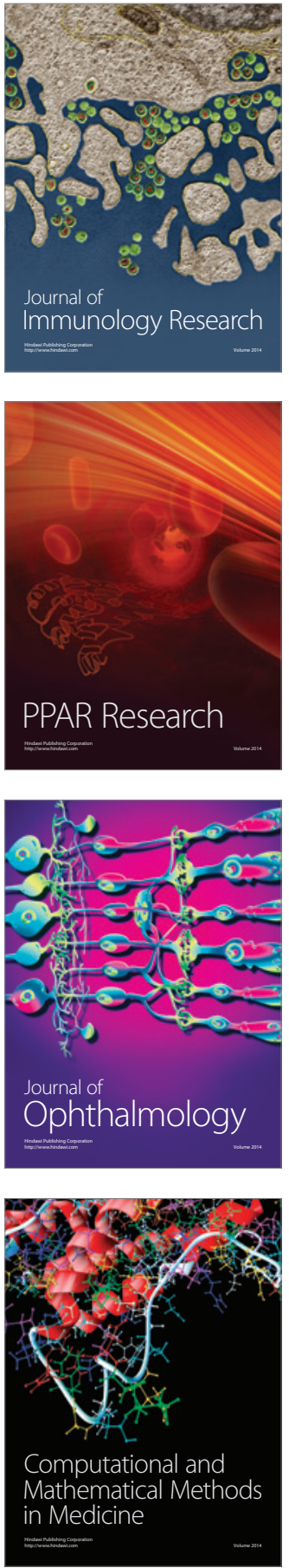

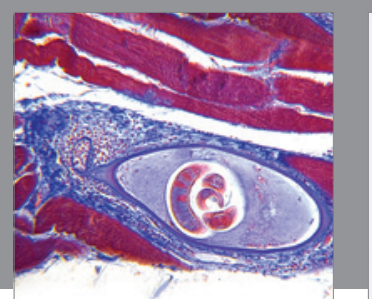

Gastroenterology Research and Practice

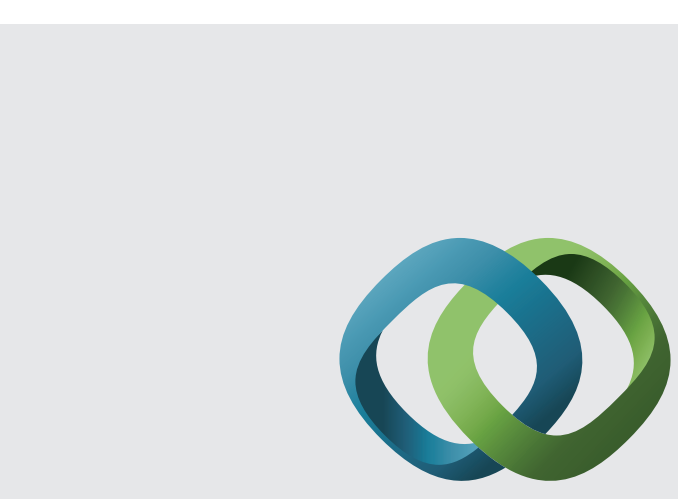

\section{Hindawi}

Submit your manuscripts at

http://www.hindawi.com
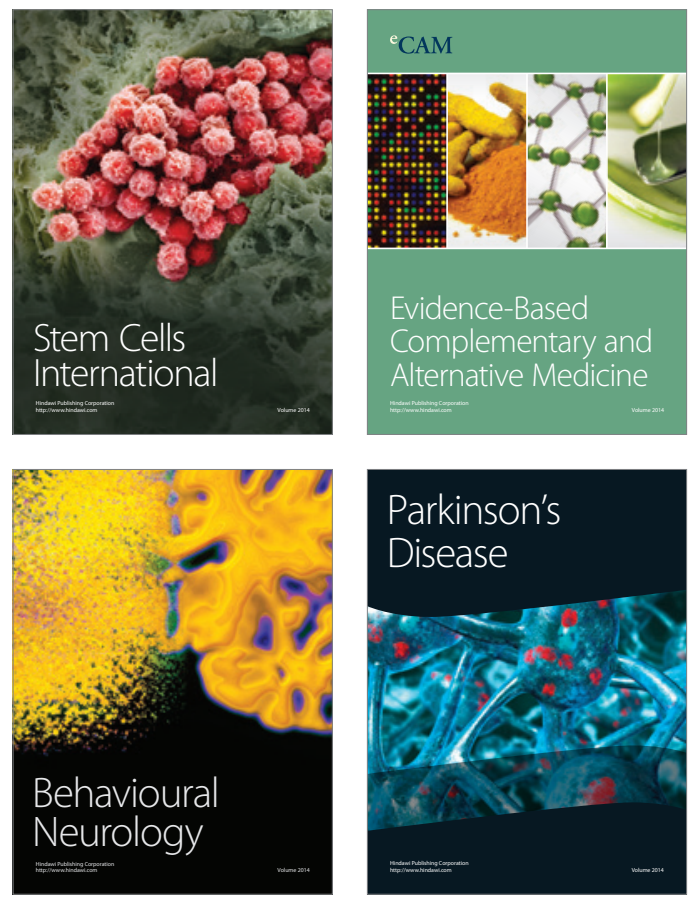
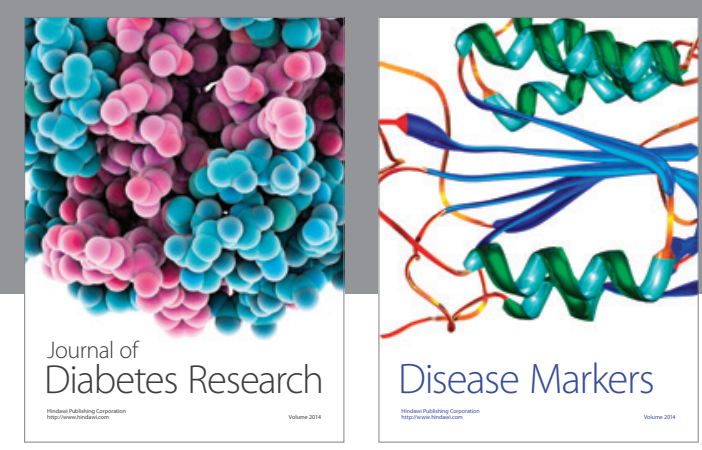

Disease Markers
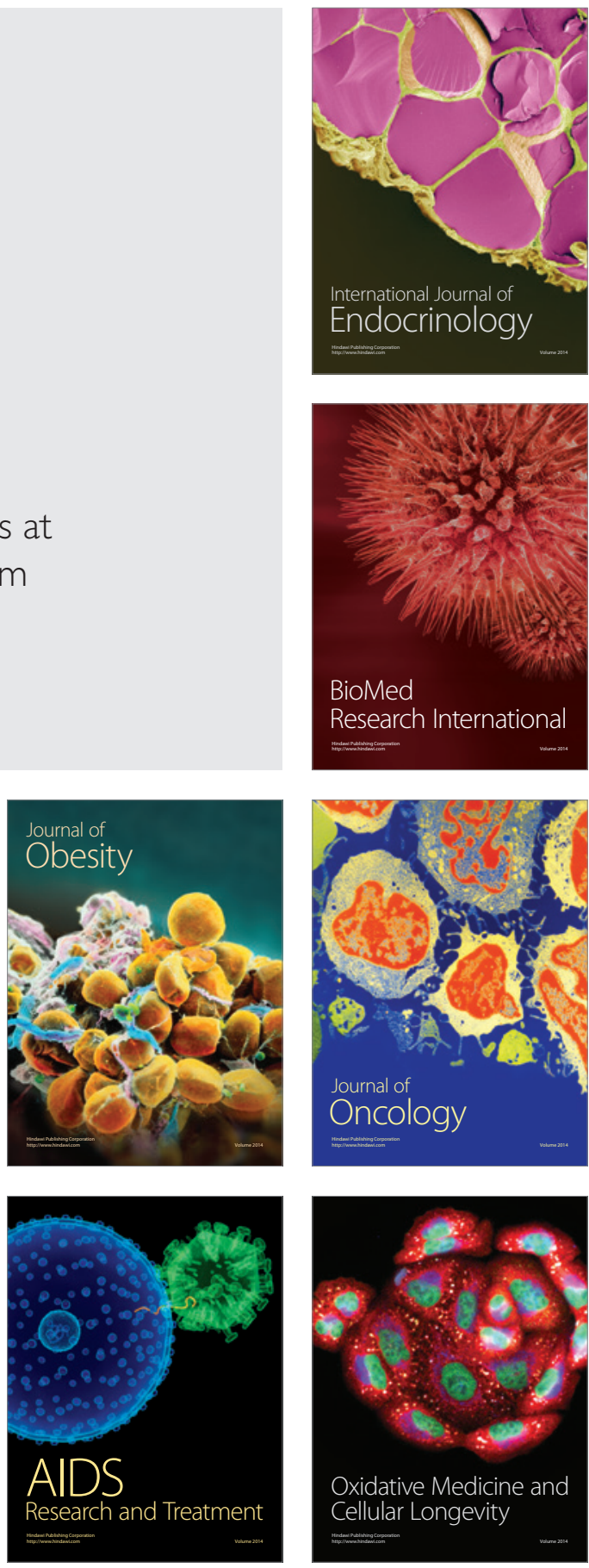